\title{
Application of abscisic acid (ABA) at veraison advanced red color development and maintained postharvest quality of 'Crimson Seedless' grapes
}

${ }^{1}$ Celia M. Cantín, ${ }^{2}$ Matthew W. Fidelibus and ${ }^{3}$ Carlos H. Crisosto*

${ }^{1}$ Departmento de Pomología, Estación Experimental de Aula Dei, Apdo. 202, 50080, Zaragoza, Spain.

${ }^{2}$ Department of Viticulture and Enology, University of California at Davis, Kearney Agricultural Center, 9240 South Riverbend Avenue, Parlier, CA 93648, USA.

${ }^{3}$ Department of Plant Sciences, University of California at Davis, Kearney Agricultural Center, 9240 South Riverbend Avenue, Parlier, CA 93648, USA.

${ }^{*}$ Corresponding author

Kearney Agricultural Center, 9240 S. Riverbend Avenue, Parlier, CA 93648, USA. Tel.: +1 559646 6596; fax: +1 559646 6593,e-mail address: carlos@uckac.edu (C.H. Crisosto).

The authors acknowledge financial support from the California Table Grape Commission, the California Competitive Grants Program for Research in Viticulture and Enology, and from Valent BioSciences. Ms. Celia M. Cant'in was supported by a FPU fellowship from Spanish MEC (Ministerio de Educación y Ciencia). We also 
acknowledge the assistance of M.Cecilia Peppi, Kimberley Cathline, and Jorge Osorio Aguilar.

\begin{abstract}
'Crimson Seedless' is a popular table grape cultivar, but in warm-climates, its fruits often fail to develop adequate red color, even after they have been treated with ethephon. Application of abscisic acid(ABA)mayimprove color more effectively than ethephon, but its potential effects on postharvest quality must be considered before recommending its use on table grapes. Therefore, we compared the postharvest quality attributes of grapes treated preharvest with $250 \mu \mathrm{LL}-1$ ethephon, the current industry standard, to that of grapes treated with 150 or $300 \mu \mathrm{LL}-1 \mathrm{ABA}$, or nontreated.

Treatment with either ethephon or $150 \mu \mathrm{LL}-1 \mathrm{ABA}$ allowed grapes to be harvested $10 \mathrm{~d}$ before nontreated fruit, and fruits treated with $300 \mu \mathrm{LL}-1$ ABA attained marketable quality $30 \mathrm{~d}$ before nontreated fruit. Early harvest was possible because the treatments induced more rapid coloring of the grapes, and though total yield was not affected by any plant growth regulator (PGR), all PGRs doubled packable yields by improving the color of the grapes. ABA-treated grapes were characterized by superior appearance both in berries and clusters' rachises compared to ethephon-treated and control grapes. Other quality attributes such as firmness, berry weight, decay incidence, and shatter remained unaffected among treatments. Therefore, ABA is an effective alternative to ethephon for enhancing the color and maintaining postharvest quality of 'Crimson Seedless' grapes.
\end{abstract}

Keywords: Ethephon; Firmness; Fruit quality; Rachis; Shatter; Storage; Vitis vinifera L. 


\section{Introduction}

In California, most 'Crimson Seedless' table grapes (Vitis vinifera L.) are grown in the San Joaquin Valley, a warm-climate region. Often, 'Crimson Seedless' grapes fail to achieve the desired level of red color, in part due to high temperatures which inhibit the accumulation of anthocyanins (Spayd et al., 2002), the class of pigments that impart red color to grape berries (Peppi et al., 2006). Applications of the plant growth regulators (PGRs) gibberellic acid ( $\left.\mathrm{GA}_{3}\right)$ and forchlorfenuron (CPPU), which may be needed to increase berry size, can further inhibit coloring. Careful canopy and crop management, and application of ethephon, optimize the color of 'Crimson Seedless' grapes (Dokoozlian et al., 1994), but even grapes subjected to these ideal cultural practices may remain poorly colored, especially when grown in regions or seasons with supraoptimal temperatures (Kliewer, 1970; Dokoozlian et al., 1994; Spayd et al., 2002). In grapes, anthocyanin accumulation begins at veraison, the onset of maturation. This accumulation appears to be regulated, at least in part, by the plant hormone abscisic acid (ABA) (Kataoka et al., 1982; Hiratsuka et al., 2001; Ban et al., 2003), and exogenous applications of ABA increased the anthocyanin content of grape skins (Peppi et al., 2006, 2007). In general, grapes having high skin anthocyanin content will appear darker and more red-colored, than grapes having low anthocyanin content, but the relationships between pigments and berry color characteristics are non-linear, so relatively large differences in pigment content may have little effect on berry color (Peppi et al., 2006, 2007). Even so, ABA treatment improved the color of 'Flame Seedless' (Peppi et al., 2006) and 'Redglobe' grapes (Peppi et al., 2007).

Historically, the cost to produce ABA was too high to justify its use as an agrochemical, but recently ABA production methods have improved sufficiently to reconsider its potential use in viticulture. Furthermore, ABA proved to be more effective than ethephon at improving the color of 'Crimson Seedless' table grapes but the most effective treatments sometimes induced berry softening (Peppi, personal communication), an undesirable condition for fresh grapes that might have further implications for their postharvest storage. Table grapes tend to senesce and deteriorate during postharvest handling (storage and marketing) which limits their market life (Crisosto and Mitchell, 
2000). Quality deterioration in clusters of grapes is expressed in terms of weight loss, rachis senescence or necrosis, berry shatter, fruit softening, undesirable color changes in the berries or rachis, and the development of fungal rots (Carvajal- Millan et al., 2001; Crisosto et al., 2002). The severity of these quality changes vary according to cultivar, and to practices in the vineyard and in the postharvest storage facility (Carvajal- Millan et al., 2001; Crisosto et al., 2002). Thus, the postharvest quality of ABA-treated grapes should be considered before recommendations on the use of ABA are made. The objective of this study was to determine whether the postharvest quality of grapes treated with different concentrations of ABA differed from that of grapes treated with $250 \mu \mathrm{LL}-1$ ethephon, a standard commercial practice, or from grapes not treated with either PGR.

\section{Materials and Methods}

\section{Plant material}

Nine-year-old own-rooted 'Crimson Seedless' grapevines (Kearney Agricultural Center, Parlier, CA) of similar capacity and crop load were used in the study. Each vine was trained to quadrilateral cordons, supported by an open gable trellis, and spur-pruned. The vines were spaced $2.4 \mathrm{~m}$ within rows and $3.6 \mathrm{~m}$ between rows. The vineyard was drip irrigated and standard cultural practices were followed, including berry thinning (2.5 $\mathrm{gGA}_{3}$ per ha at $80 \%$ anthesis), girdling for berry sizing (6mmgirdle at fruit set), basal leaf removal, and shoot thinning. Ethephon was not applied as part of the usual cultural practices (Dokoozlian et al., 1994), but was included as a treatment.

Vines were randomly assigned to receive one of four treatments; 0,150 , or 300 $\mu L L-1$ ABA, or $250 \mu L L-1$ ethephon. All PGRs were dispersed inwater with $0.05 \%(\mathrm{v} / \mathrm{v})$ adjuvant (Latron B-1956) and applied at veraison (21 July 2006) when approximately $20 \%$ of the berries on $50 \%$ of the clusters had softened. The PGRs were applied directly to the clusters with a handheld sprayer until runoff. Plastic shields prevented overspray or runoff from contacting other clusters. 


\section{Initial quality evaluations}

Clusters from each vine were harvested after most $(60 \%)$ of the fruits were considered to have exceeded the minimum market requirements of $16.5 \%$ total soluble solids (TSS), a 20:1 total soluble solids:titratable acidity ratio, and full red berry color. Only commercially acceptable clusters were harvested on any date, so plots were harvested two or three times during the harvest season. At harvest, all the harvested clusters were counted and weighed, and then each cluster was inspected and berries that were green-colored, or had other quality defects, were removed with shears and discarded. The cleaned clusters were reweighed, and then packed in Styrofoam boxes that included liners and an $\mathrm{SO}_{2}$ pad, following instructions for long distance shipping (Crisosto and Mitchell, 2000). Before sealing the boxes, 20 berries were randomly selected from each of the eight replicates (boxes) per treatment.

Skin anythocyanin content has been used to infer grape berry color, but anthocyanin content has a non-linear effect on berry color characteristics such that relatively large differences in pigment content may have little effect on berry color (Peppi et al., 2006, 2007). Thus, we measured the surface color of berries in each sample with a reflectance colorimeter (CR-200, Minolta Inc., Ramsey, NJ), using the CIELAB color system. From these data, the color index of red grapes (CIRG; Carre no et al., 1995) was calculated as CIRG $=\left(180-h_{\circ}\right) /\left(C^{*}+L^{*}\right)$, where $L^{*}$ is the lightness and corresponds to a black-white scale $\left(0\right.$, black; 100 , white), $h_{\circ}$ is the hue angle on the color wheel, and $C^{*}$ is the chroma, a measure of the intensity of color, which begins at zero (achromatic) and increases in intensity (McGuire, 1992).

Three equidistant color measurements were made around the equator of each berry; the mean values for each sample were subjected to statistical analyses. The berries of each sample were then weighed and subjected to tests with a fruit texture analyzer (FTA) (G"uss, GS.14, Strand, South Africa) which used a flat plate traveling at a speed of $5 \mathrm{mms}-1$ to compress each whole berry by $4 \mathrm{~mm}$. Peak force expressed in Newtons $(\mathrm{N})$ was recorded and considered to be an indicator of fruit firmness. These berries were then discarded, and a second sample of 20 randomly selected berries per boxwas subjected to berry retention force measurements using a digital force gauge (DPS-110R, Imada, Northbrook, Ill.). Juice from these berrieswas extracted with a hand press and filtered 
through cheesecloth. The TSS of the filtered juices were measured with a refractometer (Cambridge Instruments, Buffalo, NY), and the titratable acidities (TAs) were determined by titration of $3 \mathrm{~mL}$ of juice with $0.1 \mathrm{~N}$ sodium hydroxide $(\mathrm{NaOH})$ to an end point of $\mathrm{pH}$ 8.2 and expressed as $\mathrm{H}_{+}$mol L-1. After the berry samples were collected, the boxes were sealed and placed in cold storage at $0 \cdot \mathrm{C}$ and $85 \%$ relative humidity.

\section{Postharvest quality evaluation}

After 30 and $60 \mathrm{~d}$ of cold storage $(0 . \mathrm{C}, 85 \% \mathrm{RH})$, boxed grapes from each treatment were removed from storage, and fruit quality was evaluated. At both times, the overall visual appearance of the boxed grapes was rated according to the following scale: (1) excellent, (2) acceptable, or (3) commercially unacceptable. Rachis condition was then rated according to Crisosto et al. (2002), as follows: (1) healthy = entire rachis including the pedicels green and healthy, (2) slight $=$ rachis in good condition, but noticeable browning of pedicels, (3) moderate = browning of pedicels and secondary rachis, or (4) severe = pedicels, secondary, and primary rachis completely brown. Berry shatter was evaluated for each box at the end of the cold storage ( $60 \mathrm{~d})$ by subtracting the weight of free berries from the total boxed grape weight and expressed as percentage of shatter in each box.

\section{Statistical analysis}

All data were subjected to analysis of variance using SAS statistical software (SAS Institute, Cary, NC). The model tested for main effects of storage time ( $30 \mathrm{~d}$ versus $60 \mathrm{~d}$ ) and treatment, and for the potential interaction of storage time - treatment. When appropriate, means were separated according to $\operatorname{LSD}(\alpha=0.05)$. 


\section{Results and discussion}

\section{Initial quality}

Clusters of grapes attained marketable quality between 22 August and 3 November, depending on the treatments they received. Grapes treated with $300 \mu L L-1$ ABA colored quickly and thus were harvestable about $30 \mathrm{~d}$ earlier than untreated grapes, and $10 \mathrm{~d}$ earlier than grapes treated with ethephon (Table 1). On average, grapes treated with $150 \mu \mathrm{LL}-1$ ABA were harvestable at about the same time as grapes treated with $300 \mu \mathrm{LL}-1$ ABA or ethephon, and grapes treated with either $150 \mu \mathrm{LL}-1$ ABA or ethephon were harvestable about $15 \mathrm{~d}$ before nontreated grapes.

Although PGR treatment advanced harvest date, it did not affect yield or berry weight (Table 1) as observed by others (D“uring et al., 1978; Lee et al., 1997; Peppi et al., 2006). However, each of the PGR treatments doubled the percentage of packable fruit (Table 1) by improving the proportion of fruit that were well colored. Regardless of treatment, the packed fruit were similar with respect to $h^{\circ}, L^{*}$, and CIRG color index (Table 1), confirming that a uniform standard was used to select fruit for harvest and packing. With respect to color, $C^{*}$ was the only variable that differed among treatments; fruits treated with $300 \mu \mathrm{LL}-1$ ABA had a lower $C^{*}$ than nontreated fruits which suggests that the treated fruits had a slightly less pure color (Mc Guire, 1992; Carre no et al., 1995) than the nontreated fruits, but this slight effectwas not perceived by the naked eye. Based on the CIRG color index, all grapes could be classified as pink-colored $(2<\mathrm{CIRG}<4)\left(\mathrm{Carre}^{\sim}\right.$ no et al., 1995). It is notable that grapes treated with ABAor ethephon were essentially the same color as untreated grapes even though grapes from different treatments were harvested as much as one month apart.

The $\mathrm{ABA}$ and ethephon treatments did not affect berry compression or removal force (Table 1), so the PGRs in this study did not seem to affect firmness or predispose the fruit to postharvest shatter. However, TSS, TA, and the ratio of TSS to TA, differed among treatments. Grapes treated with $300 \mu \mathrm{LL}-1$ ABA were harvested at the lowest TSS, followed by grapes treated with $150 \mu \mathrm{LL}-1 \mathrm{ABA}$, and grapes treated with ethephon or nontreated. Grapes treated with $300 \mu \mathrm{LL}-1$ ABA or ethephon had the highest acidity 
( $5.0 \mathrm{gL}-1)$ and the lowest TSS:TA ratio. It is likely that the differences in fruit composition among treatments were mainly due to the earlier harvest of fruits treated with ABA compared to those treated with ethephon or nontreated. Others have reported that application of $\mathrm{ABA}$ had little or no effect on the grape soluble solids or titratable acidity (Han et al., 1996; Lee et al., 1997; Jeong et al., 2004; Peppi et al., 2006). In any case, all of the fruit surpassed minimum quality standards.

\section{Postharvest quality evaluation}

After $30 \mathrm{~d}$ in cold storage, grapes had similar firmness regardless of the preharvest treatment to which they were subjected (Table 2). Berry compression force decreased in storage, as expected, but again there were no preharvest treatment effects on this variable after $60 \mathrm{~d}$ cold storage (Table 2). Although it is accepted that ethephon treatments may cause undesirable softening of grapes (Jensen et al., 1975), this effect is not consistent as it has been observed in our and otherworks (Peppi et al., 2006, 2007). The effect of ABA on fruit firmness has not been widely tested. An application of 500-1000 $\mu \mathrm{LL}-1$ ABA caused berry softening in 'Crimson Seedless', but 75-300 $\mu$ LL-1 ABA did not (Fidelibus, personal communication), confirming our results. Therefore, ABA concentration is critical in order to achieve better color and at the same time to maintain postharvest quality of table grapes.

Visual appearance of the boxed grapes, and rachis browning, worsened between 30 and $60 \mathrm{~d}$ cold storage (Table 2). Grapes treated with $300 \mu \mathrm{LL}-1$ ABA had the best visual appearance after $30 \mathrm{~d}$ of storage, and after $60 \mathrm{~d}$, they had a better appearance than grapes treated with ethephon (Table 2). Likewise, grapes treated with 150 or $300 \mu \mathrm{LL}-1$ ABA had the lowest rachis browning score after 30 or $60 \mathrm{~d}$ of cold storage. We believe that the later harvest of ethephon-treated or untreated fruits may have allowed the rachis to initiate senescence related processes before packing which were expressed as an earlier development of browning during cold storage. However, berry shatter after $60 \mathrm{~d}$ of cold storage was similar, regardless of treatment (Table 2), a finding that agrees with the lack of differences in fruit retention force discussed earlier. In conclusion, treatment with 300 $\mu$ LL-1 ABA advanced harvest date of 'Crimson Seedless' by 10-30 d, compared to grapes treated with ethephon, or nontreated. Application of ABA advanced harvest date 
because it rapidly improved grape color. Many nontreated grapes never achieved adequate color, so treatment with ABA or ethephon doubled the packable yield.

Treatment with ABA did not reduce grape quality in any way; and after cold storage the appearance of boxed ABA-treated grapes was superior to that of boxed grapes treated with ethephon or nontreated. Thus, treatment with ABA is an effective alternative to treatment with ethephon to improve the color of 'Crimson Seedless' grapes, with the added benefit of improving the visual appearance of stored grapes and reducing the rate of rachis browning during postharvest storage. 


\section{References}

Ban, T., Ishimaru, M., Kobayashi, S., Shiozaki, S., Goto-Yamamoto, N., Horiuchi, S., 2003. Abscisic acid and 2,4-dichlorophenoxyacetic acid affect the expression of anthocyanin biosynthetic pathway genes in 'Kyoho' grape berries. J. Hortic. Sci. Biotechnol. 78, 586-589.

Carreño, J., Martinez, A., Almela, L., Fernandez-Lopez, J.A., 1995. Proposal of an index for the objective evaluation of the colour of red table grapes. Food Res. Int. 28, $373-377$.

Carvajal-Millan, E., Carvallo, T., Orozco, J.A., Martinez, M.A., Tapia, I., Guerrero, V.M., Rascon-Chu, A., Llamas, J., Gardea, A.A., 2001. Polyphenol oxidase activity, color changes, and dehydration in table grape rachis during development and storage as affected by n-(2-chloro-4-pyridyl)-nphenylurea. J. Agric. Food Chem. 49, 946-951.

Crisosto, C.H., Mitchell, F.G., 2000. Postharvest handling systems: small fruits. I. Table grapes, Chapter 29. In: Kader, A.A. (Ed.), Postharvest Technology of Horticultural Crops, Third ed. DANR Publication \#3311.

Crisosto, C.H., Garner, D., Crisosto, G., 2002. Carbon dioxide-enriched atmospheres during cold storage limit losses from botrytis but accelerate rachis browning of 'Redglobe' table grapes. Postharvest Biol. Technol. 26, 181-189.

Dokoozlian, N.K., Luvisi, D.A., Schrader, P.L., Moriyama, M.M., 1994. Influence of trunk girdle timing and ethephon on the quality of Crimson Seedless table grapes. In: Rantz, J.M. (Ed.), International Symposium on Table Grapes Production Proceedings, June 28-29. Anaheim, CA, pp. 237-240.

D“uring, H., Alleweldt, G., Koch, T., 1978. Studies on hormonal control of ripening in berries of grape vines. Acta Hortic. 80, 397-405.

Han, D.H., Lee, S.M., Kim, S.B., 1996. Effects of ABA and ethephon treatments on coloration and fruit quality in Kyoho grape. J. Kor. Soc. Hortic. Sci. 37, 416-420.

Hiratsuka, S., Onodera, H., Kawai, Y., Kubo, T., Itoh, H.,Wada, R., 2001. ABA and sugar effects on anthocyanin formation in grape berry cultured in vitro. Sci. Hortic. 90, 121-130. 
Jensen, F.L., Kissler, J., Peacock, W., Leavitt, G., 1975. Effect of ethephon on color and fruit characteristics of Tokay and Emperor table grapes. Am. J. Enol. Viticult. $26,79-81$.

Jeong, S.T., Goto-Yamamoto, N., Kobayashi, S., Esaka, M., 2004. Effects of plant hormones and shading on the accumulation of anthocyanins and the expression of anthocyanin biosynthetic genes in grape berry skins. Plant Sci. 167, 247-252.

Kataoka, I., Sugiura, A., Utsunomiya, N., Tomana, T., 1982. Effect of abscisicacid and defoliation on anthocyanin accumulation in Kyoho grapes (Vitis vinifera L. $\times$ V. labruscana Bailey). Vitis 21, 325-332.

Kliewer, W.M., 1970. Effect of day temperature and light intensity on coloration of Vitis vinifera L. grapes. J. Am. Soc. Hortic. Sci. 95, 693-697.

Lee, K.S., Lee, J.C.,Hwang,Y.S., Hur, I.B., 1997. Effects of natural type (S)-(+)abscisic acid on anthocyanin accumulation and maturity in 'Kyoho' grapes. J. Kor. Soc. Hortic. Sci. 38, 717-721.

McGuire, R.G., 1992. Reporting of objective color measurements. Hortic. Sci. 27, $1254-1255$.

Peppi, M.C., Fidelibus, M.W., Dokoozlian, N., 2006. Abscisic acid application timing and concentration affect firmness, pigmentation, and color of 'Flame Seedless' grapes. Hortic. Sci. 41, 1440-1445.

Peppi, M.C., Fidelibus, M.W., Dokoozlian, N., 2007. Application timing and concentration of abscisic acid affect the quality of 'Redglobe' grapes. J. Hortic. Sci. Biotechnol. 82, 304-310.

Spayd, S.E., Tarara, J.M., Mee, D.L., Ferguson, J.C., 2002. Separation of sunlight and temperature effects on the composition of Vitis vinifera cv. Merlot berries. Am. J. Enol. Viticult. 53, 171-182. 

Table 1. Influence of ABA and ethephon treatments at veraison on quality attributes of 'Crimson Seedless' grapes measured at harvest time.

\begin{tabular}{|c|c|c|c|c|c|c|c|c|c|c|c|c|c|}
\hline Treatment & $\begin{array}{c}\text { Days } \\
\text { After } \\
1^{\text {st }} \text { harvest } \\
\end{array}$ & $\begin{array}{l}\text { Yield } \\
(\mathrm{kg})\end{array}$ & $\begin{array}{c}\% \\
\text { Packed }\end{array}$ & $\begin{array}{c}\text { Berry } \\
\text { weight } \\
\text { (g) }\end{array}$ & Color $\mathrm{L}^{*}$ & Color C* & Color $\mathrm{h}^{*}$ & CIRG & $\begin{array}{l}\text { Abscission } \\
\text { (N) }\end{array}$ & $\begin{array}{l}\text { FTA } \\
(\mathrm{N})\end{array}$ & $\begin{array}{l}\text { SSC } \\
(\%)\end{array}$ & $\begin{array}{l}{ }^{z_{T A}} \\
(\%)\end{array}$ & SSC/TA \\
\hline Control & 42.1 & 32.5 & 42.3 & 5.4 & 35.1 & 11.8 & 27.3 & 3.3 & 3.08 & 18.57 & 20.6 & 0.45 & 46.6 \\
\hline 150 ppm ABA & 19.6 & 34.8 & 83.8 & 5.8 & 35.6 & 10.9 & 23.1 & 3.4 & 4.31 & 18.24 & 18.8 & 0.48 & 39.9 \\
\hline 300 ppm ABA & 9.5 & 35.2 & 86.4 & 5.9 & 34.6 & 9.9 & 21.6 & 3.6 & 3.05 & 17.37 & 18.5 & 0.54 & 34.8 \\
\hline 250 ppm Ethephon & 27.6 & 28.0 & 74.8 & 5.5 & 34.5 & 11.3 & 21.8 & 3.5 & 3.52 & 18.00 & 19.6 & 0.48 & 40.9 \\
\hline${ }^{Y}$ LSD & 12.74 & 10.38 & 20.65 & 0.55 & 1.21 & 1.35 & 7.89 & 0.24 & 1.55 & 2.39 & 0.92 & 0.06 & 6.21 \\
\hline$p$-value & $<0.0001$ & 0.4758 & 0.0005 & 0.1973 & 0.2805 & 0.0389 & 0.4365 & 0.0832 & 0.3229 & 0.7689 & 0.0003 & 0.0451 & 0.0083 \\
\hline
\end{tabular}

${ }^{\mathrm{Z}}$ Grams tartaric acid per $100 \mathrm{ml}$ juice.

${ }^{\mathrm{Y}}$ Mean separation by LSD test at $\mathrm{P}>0.05$. 
Table 2. Influence of ABA and ethephon treatment at veraison on shelf life attributes of 'Crimson Seedless' grapes measured after 30 and 60 days of cold storage at $0^{\circ} \mathrm{C}$ and $85 \% \mathrm{RH}$.

\begin{tabular}{|c|c|c|c|c|c|c|c|}
\hline \multirow{2}{*}{ Treatment } & \multicolumn{2}{|c|}{ FTA (N) } & \multicolumn{2}{|c|}{${ }^{z}$ Visual appearance (1-3) } & \multicolumn{2}{|c|}{${ }^{Y}$ Stem Browning (1-4) } & \multirow{2}{*}{$\begin{array}{c}\text { Shatter }(\%) \\
60 \text { days }\end{array}$} \\
\hline & 30 days & 60 days & 30 days & 60 days & 30 days & 60 days & \\
\hline Control & 17.2 & 15.1 & 1.8 & 1.7 & 2.2 & 3.7 & 6.0 \\
\hline 150 ppm ABA & 17.8 & 16.6 & 1.7 & 1.7 & 1.6 & 2.7 & 4.9 \\
\hline 300 ppm ABA & 17.6 & 15.2 & 1.1 & 1.4 & 1.3 & 2.6 & 7.4 \\
\hline 250 ppm Ethephon & 18.2 & 16.3 & 1.7 & 2.0 & 2.0 & 3.1 & 6.7 \\
\hline$x_{\text {LSD }}$ & 1.93 & 2.24 & 0.29 & 0.34 & 0.56 & 0.42 & 3.33 \\
\hline$p$-value & 0.7993 & 0.3928 & $<0.0001$ & 0.0091 & 0.0083 & $<0.0001$ & 0.5003 \\
\hline
\end{tabular}

${ }^{\mathrm{Z}}$ Berry appearance was evaluated using the following score system: (1) excellent, (2) acceptable and, (3) reject.

Y Stem browning symptoms were evaluated using the following score system: (1) healthy, (2) slight, (3) moderate, and (4) severe.

${ }^{\mathrm{x}}$ Mean separation by LSD test at $\mathrm{P}>0.05$. 